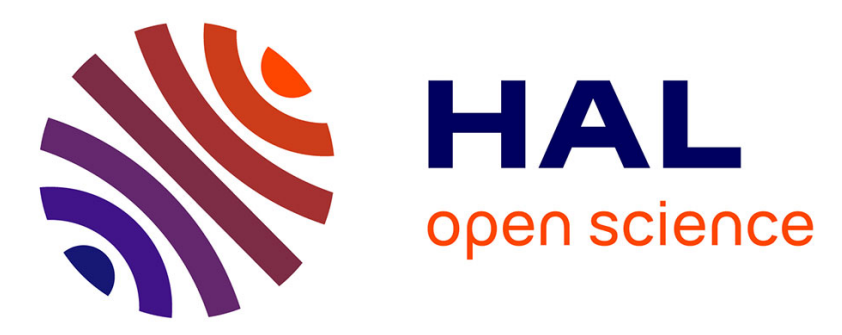

\title{
Position modulated tangential photopyroelectric (PPE) spectrometry for low absorptions in liquids
}

\author{
M. Chirtoc, Z. Bozoki, D. Bicanic, J. Gibkes
}

\section{To cite this version:}

M. Chirtoc, Z. Bozoki, D. Bicanic, J. Gibkes. Position modulated tangential photopyroelectric (PPE) spectrometry for low absorptions in liquids. Journal de Physique IV Proceedings, 1994, 04 (C7), pp.C7-63-C7-66. 10.1051/jp4:1994716 . jpa-00253219

\section{HAL Id: jpa-00253219 https://hal.science/jpa-00253219}

Submitted on 1 Jan 1994

HAL is a multi-disciplinary open access archive for the deposit and dissemination of scientific research documents, whether they are published or not. The documents may come from teaching and research institutions in France or abroad, or from public or private research centers.
L'archive ouverte pluridisciplinaire HAL, est destinée au dépôt et à la diffusion de documents scientifiques de niveau recherche, publiés ou non, émanant des établissements d'enseignement et de recherche français ou étrangers, des laboratoires publics ou privés. 


\title{
Position modulated tangential photopyroelectric (PPE) spectrometry for low absorptions in liquids
}

\author{
M. Chirtoc*,****, Z. Bozoki**, D. Bicanic*** and J, Gibkes**** \\ * Inst. Isotopic and Molec. Technol., P.O. Box 700, 3400 Cluj 5, Romania \\ ** Inst. Isotopes, P.O. Box 77, 1525 Budapest, Hungary \\ *** Laser Photoacoustic Lab., Agric. Univ., Bomenweg 4, 6703 HD Wageningen, The Netherlands \\ **** Ruhr-Univ., Inst. Exper. Phys. III, AG Solid State Spectrosc., 44780 Bochum, Germany
}

\begin{abstract}
A novel tangential photopyroelectric (PPE) cell for liquids is described in which the excitation laser beam is position-modulated. As a result, only the thermal wave is modulated and the background signal due to scattered light is suppressed by more than 50 times. The application for water pollution monitoring shows a detection limit of $1 \mathrm{mmol} / \mathrm{m}^{3}$ ammonium ion in water.
\end{abstract}

\section{INTRODUCTION}

Direct coupling photothermal (PT) methods are more efficient than gas coupled techniques for measuring low absorptions in condensed samples. By the detection of acoustic waves with PZT-type cylindrical or localized detectors, absorption limits below $10^{-8} \mathrm{~cm}^{-1}$ were demonstrated [1]. Few works were dedicated to the direct detection of thermal waves arising from radiation absorption in liquids. If a pyroelectric sensor is placed within a few thermal diffusion lengths $(<1 \mathrm{~mm}$ at $1 \mathrm{~Hz}$ ) away from the location of the radiation absorption, the pyroelectric response dominates the piezoelectric one. With the photopyroelectric (PPE) method adapted to liquid samples [2-4], a detection limit of $1.6 \times 10^{-4} \mathrm{~cm}^{-1}$ was reported with pulsed excitation [5]. In the standard PPE configuration with periodic excitation the signal from quasi-transparent samples is masked by direct absorption of the excitation radiation in the sensor itself [6]. To avoid this, in the reflection configuration (RPPE) the sensor is provided with a reflecting electrode [7], whereas in the tangential configuration (TPPE) the background signal is due only to the light fraction scattered at the cell windows and at the impurities in the sample.

The position modulation with switched $[8,9]$, linear $[10,11]$ or elliptical [12] shapes has been used in photoacoustics and PT radiometry for improving the depth resolution or for oriented structure enhancement. This paper describes a tangential PPE cell in which the intensity modulation of the excitation beam is replaced by a position modulation achieved with an oscillating mirror, Fig.1a. In this way the scattered light directly reaching the sensor is not modulated, and the detector is subjected only to the periodic temperature field arising from the absorption of continuous radiation in the sample.

\section{THEORY}

The schematic lay-out of the PPE cell is shown in Fig. 1b. The continuous line heat source produces a temperature field with axial symmetry, moving periodically in the vertical plane with angular 


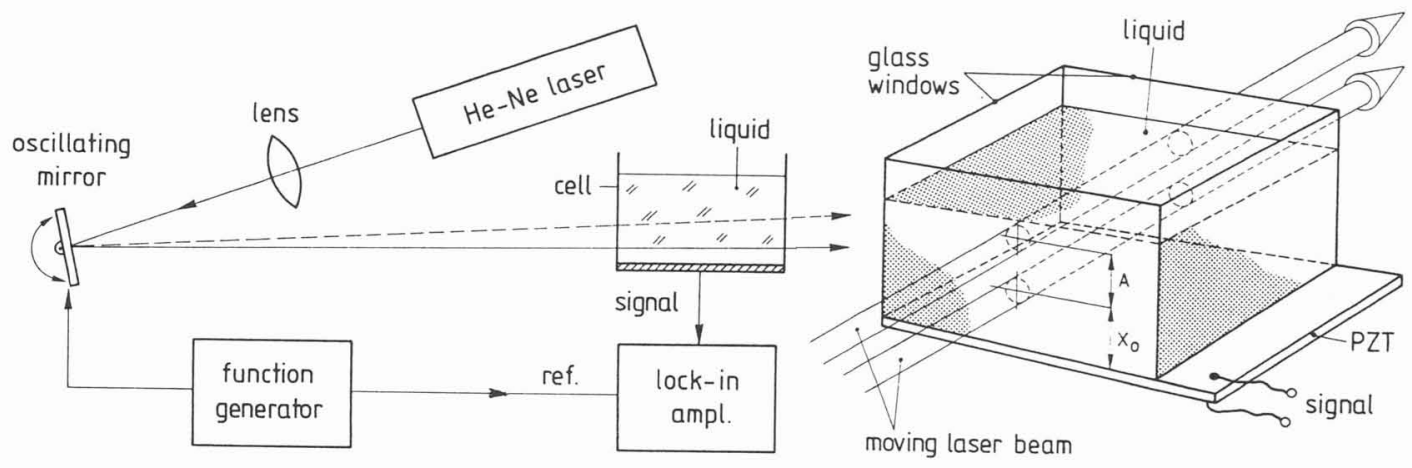

Fig. 1 Set up for position modulated, tangential PPE spectrometry (a), and the cell design illustrating the modulation geometry (b).

frequency $\omega$ at distance $x(t)$ from the sensor surface, according to:

$$
x(t)=x_{0}+\frac{A}{2}[1+\sin (\omega t)]
$$

for sine modulation, or:

$$
x(t)=\left\{\begin{array}{lll}
x_{0}+A & \text { if } & 2 k \pi / \omega<t<(2 k+1) \pi / \omega \\
x_{0} & \text { if } & (2 k+1) \pi / \omega<t<2(k+1) \pi / \omega
\end{array}\right.
$$

for square modulation $(k=0,1,2, \ldots)$. Considering a laser beam with power $\mathbf{P}$ having Gaussian profile of radius a, the line heat source in the limit of low absorption coefficient $B$ is expressed as:

$$
Q(x, y, t)=\frac{2 \beta P}{\pi a^{2}} \exp \left(-2 \frac{x^{2}(t)+y^{2}}{a^{2}}\right)
$$

For the determination of the temperature field, we used the solution for an intensity modulated line heat source [13], and we replaced the modulation $P(t)$ by a position modulation $x(t)$. Thus one obtains:

$$
T(x, y, t)=\frac{2 \beta P}{\pi \rho C} \int_{0}^{t} \exp \left(-2 \frac{x^{2}(\tau)+y^{2}}{8 \alpha(t-\tau)+a^{2}}\right)\left[8 \alpha(t-\tau)+a^{2}\right]^{-1} d \tau
$$

where $\rho \mathrm{C}$ and $\alpha$ are the volume specific heat and the thermal diffusivity. The pyroelectric signal is proportional to the average temperature in the plane of the detector, obtained by integration of Eq.(4) over the $y$-coordinate. The result is:

$$
S(t)=\sqrt{\frac{2}{\pi}} \frac{\beta P}{\rho C L} \int_{0}^{t} \exp \left(\frac{-2 x^{2}(\tau)}{8 \alpha(t-\tau)+a^{2}}\right)\left[8 \alpha(t-\tau)+a^{2}\right]^{-1 / 2} d \tau
$$

where $L$ is the equivalent width of the active detector surface.

\section{EXPERIMENTAL RESULTS AND DISCUSSION}

In the set up of Fig. 1 , the lens with $f=200 \mathrm{~mm}$ concentrates the $P=1 \mathrm{~mW}$ HeNe laser beam into 

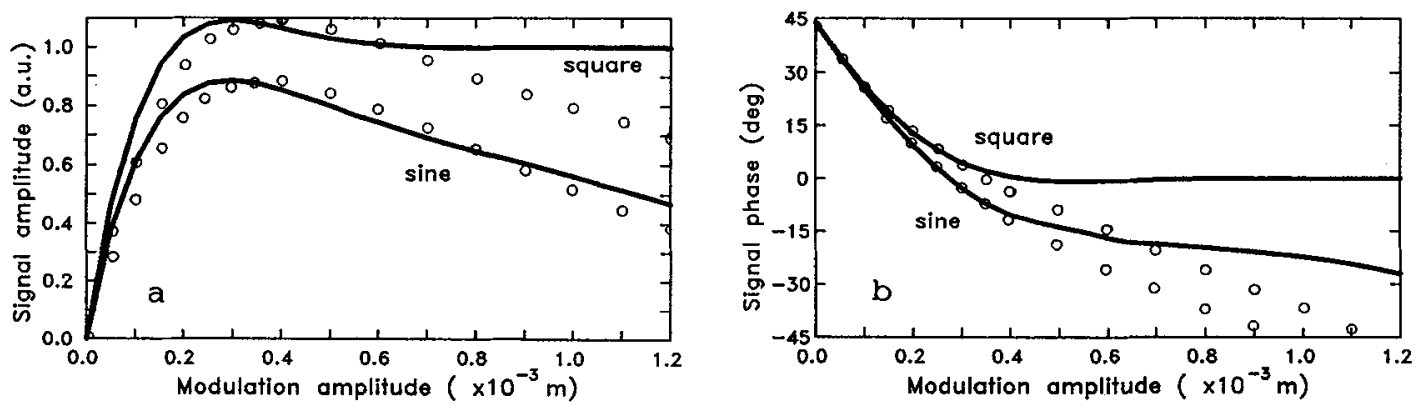

Fig. 2 Signal $S(t)$ amplitude and phase vs. modulation amplitude $A$ (sine and square wave), normalized to the signal obtained with intensity modulation (with chopper, $A=0$ ). Parameter values are: $x_{0}=0.4 \mathrm{~mm}$, $f=2.55 \mathrm{~Hz}, B=0.35 \mathrm{~cm}^{-1}\left(1.77 \times 10^{-7} \mathrm{M}\right.$ methylene blue solution). Solid lines: theory; circles: experiment.

the middle of the cell, to a beam radius of $\mathrm{a}=50 \mu \mathrm{m}$. The cell with $4 \times 4 \times 4 \mathrm{~mm}^{3}$ has lateral windows made of microscope glass platelets and the bottom is a $0.2 \mathrm{~mm}$ thick PZT-type ceramic sensor, provided with gold electrodes and having a capacitance of 740pF. The Ithaco Dynatrac lock-in amplifier has an input impedance of $100 \mathrm{Mohm}$. The mirror is driven by sine or square wave voltage. For the intensity modulation, it has a fixed position and a chopper with 0.5 filling factor is used (not shown in Fig.1a). The thermal diffusion length in water is $\mu=(\alpha / \pi \mathrm{f})^{1 / 2}=0.135 \mathrm{~mm}$ at the working frequency of $2.55 \mathrm{~Hz}$.

The comparison between theory and experiment is shown in Fig.2. As expected, the signal amplitude first increases and then reaches a maximum. In the case of square wave modulation there is an $8 \%$ overshoot in the theoretical curve. This is because the position modulated $\mathrm{cw}$ beam is equivalent to the effect of two virtual beams with fixed positions at $x_{0}$ and $x_{0}+A$, modulated in intensity with the same frequency and opposed phases. The sensor feels the vector sum of these two heat sources. The estimation assuming plane thermal waves predicts the first constructive interference at $A / \mu=\pi$, i.e., $A=0.42 \mathrm{~mm}$. The computation based on Eq.(5) yields a lower value, $A=0.3 \mathrm{~mm}$, but the experimental maximum is shifted to $A=0.4 \mathrm{~mm}$. The maximum is small due to the strong damping of the second virtual beam $[\exp (-\pi)=0.043$, and the minimum at $A / \mu=2 \pi(A=0,84)$ can no longer be observed. For large A values, the signals obtained with mirror and chopper should be equal, since the two modulation methods are then equivalent. The experimental amplitude and phase decrease however, due to the mechanical inertia of the moving mirror. For the same reason there is an increasing phase lag at large A values (Fig.2b).

The experimental points for the sine modulation are closer to the theoretical curves as the mirror position follows more easily the sine than the square driving voltage. With increasing $A$, the signal amplitude is decreasing steadily because during one period the beam spends less time at $x_{0}$, in the neighborhood of the detector, which is not the case for square modulation.

Fig. 3 is a comparative investigation of the signal-to-background ratio for position and intensity modulation. At low distances $x_{0}$ from the sensor there is some contribution to the mirror modulated background signal from stray light in the laser beam waist. The proof is the sharp decrease according to $\exp \left(-\mathrm{x}_{0}{ }^{2}\right)$. The chopper modulated background signal is up to 100 times higher. The signal with the test solution follows the theoretical curve as long as it surpasses the background level. The best trade-off between signal amplitude and background level is for $x_{0}=0.4 \mathrm{~mm}$, where the background suppression factor is $\mathbf{5 0}$. With improved irradiation focussing $x_{0}$ can be decreased (sensor closer to laser beam), thus improving the dynamic range for the absorption coefficient measurement.

Fig. 4 shows the results of an application to water pollution monitoring, corrected for the signal with distilled water. The minimum detectable concentration of $1 \mathrm{mmol} / \mathrm{m}^{3}$ of ammonium in water is determined by the blank absorption and is comparable to the value reported in other PT experiments [14]. 


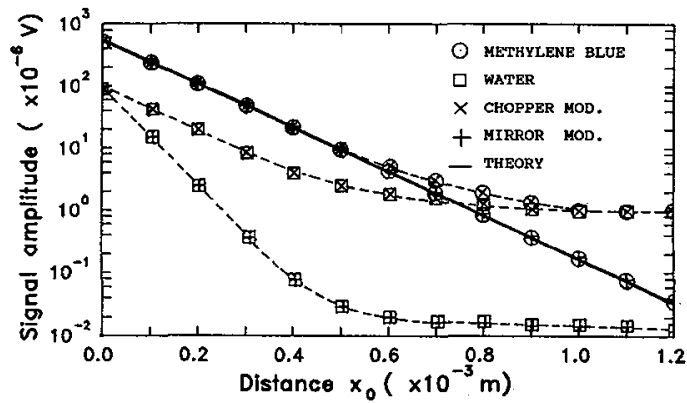

Fig. 3 Comparison between mirror $(A=0.3 \mathrm{~mm})$ and chopper $(A=0 \mathrm{~mm})$ modulation for the absorption signal (methylene blue) and background (distilled water).

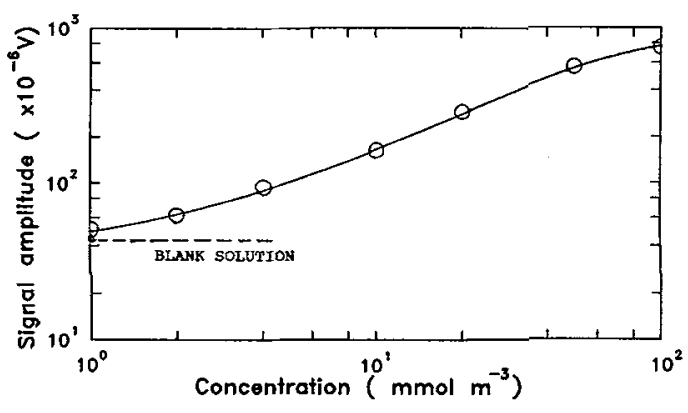

Fig. 4 TPPE signal for a set of ammonium ion solutions, prepared according to the indophenol colorimetric reaction [9]. Parameter values are: $\mathrm{x}_{0}=0.2 \mathrm{~mm}, \mathrm{~A}=0.42 \mathrm{~mm}$.

\section{CONCLUSIONS}

The results obtained with a tangential PPE cell with sine and square position modulation, are well explained by the theoretical model. The optimum experimental parameters were determined $\left(\mathrm{x}_{0}=0.4 \mathrm{~mm}, \mathrm{~A}=0.3 \mathrm{~mm}\right)$ and an enhancement of the maximum signal in the case of square modulation was observed, due to an interesting effect of thermal wave interference. The background signal is efficiently suppressed and it is reported an application to water pollution monitoring. Possible future applications concern the possibility to discriminate true absorption from scattering in turbid solutions.

Acknowledgements: One of the authors (M.Chirtoc) acknowledges the support received from the NWO Organization (The Netherlands) and Humboldt Foundation (Germany) during the preparation of this work.

\section{REFERENCES}

[1] Sawada T. and Kitamori T., "Analytical Applications of Photoacoustic Spectroscopy to Condensed Phase Substances", Physical Acoustics Vol. XVIII, Mason W.P. and Thurston R.N., Eds. (Academic Press, Inc., San Diego, 1988).

[2] Chirtoc M., Dadarlat D., Chirtoc I. and Bicanic D.D., Spectroscopy Lett. 21 (1988) 413.

[3] Hinoue T., Kawata S. and Yokohama Y., Chem.Lett. 1988 (1988) 2061.

[4] Antoniow J.S., Egee M. and Chirtoc M., in this volume.

[5] Hinoue T., Kaji J. and Yokohama Y., Analytical Chem. 63 (1991) 2086.

[6] Chirtoc M. and Mihailescu G., Phys.Rev. B40 (1989) 9606.

[7] Chirtoc M., Dadarlat D. and Bicanic D., "Standard Versus New Photopyroelctric (PPE) Techniques: Reflection (RPPE) and Inverse (IPPE) Configurations" Photoacoustic and Photothermal Phenomena III, Vol.69, Bicanic D., Ed. (Springer Verlag, Berlin, 1992) p.103.

[8] Busse G. and Renk K.F., Appl. Phys. Lett. 42 (1983) 366.

[9] Zuccon J.F. and Mandelis A., IEEE Trans. UFFC 35 (1988) 5.

[10] Busse G. and Ograbeck A., J. Appl. Phys. 51 (1980) 3576.

[11] Quimby R.S., Appl. Phys. Lett. 45 (1984) 1037.

[12] Busse G., Optics Comm. 36 (1981) 441.

[13] Vyas R., Monson B., Nie Y.-Z. and Gupta R., Appl.Opt. 27 (1988) 3914.

[14] Strauss E., Favier J.-P., Bicanic D., van Asselt K. and Lubbers M., Analyst 116 (1991) 77. 